
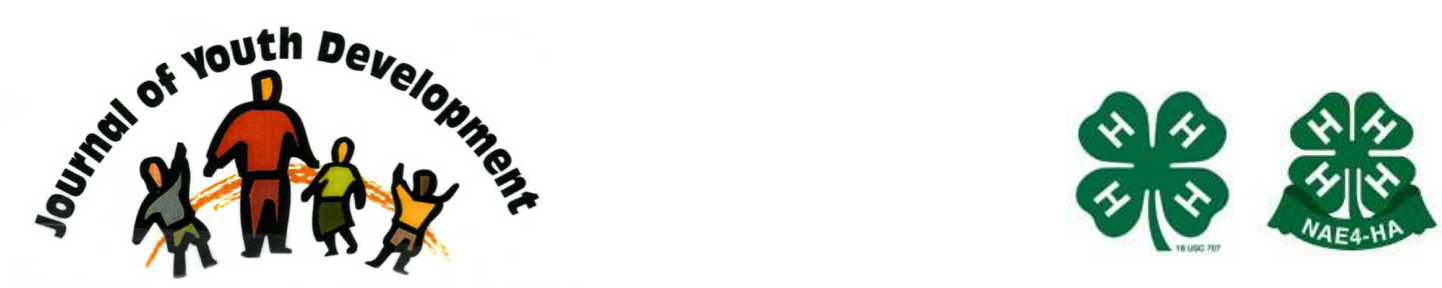

Bridging Research \& Practice

\title{
Exploring Overparenting within the Context of Youth Development Programs
}

\author{
Barry A. Garst \\ Department of Parks, Recreation, \& Tourism Management \\ Clemson University \\ Clemson, SC \\ bgarst@clemson.edu \\ Ryan J. Gagnon \\ Department of Parks, Recreation, \& Tourism Management \\ Clemson University \\ Clemson, SC
}




\title{
JOURNAL OF YOUTH DEVELOPMENT \\ bridging research and practice
}

\section{Exploring Overparenting within the Context of Youth Development Programs}

\author{
Barry A. Garst and Ryan J. Gagnon \\ Clemson University
}

\begin{abstract}
While normative parenting styles can result in positive youth outcomes such as adjustment and competence, overparenting may lead to a variety of negative youth outcomes including poor self-regulation and childhood anxiety. Conceptualizations of overparenting vary and an opportunity exists to clarify the construct and consider the implications for youth development settings. This paper synthesizes what is known about overparenting and its subdimensions, proposes an overparenting model built on prior research, and explores the influence of overparenting on youth development programs. An agenda for further overparenting research is proposed.
\end{abstract}

\section{Introduction}

In 1945, the New York Times published an article titled, "The Teen-Age Bill of Rights," which become symbolic of the emergence of youth culture and a benchmark in the recognition of adolescence as a unique period of life (Savage, 2007). Included in this list of ten rights was the theme, "The right to make mistakes, to find out for oneself." Sixty years later, the relevance of allowing a child to fail, and to learn the lessons that accompany failure, has never been more poignant in the face of modern hyper-involved parenting (Tough, 2012). From unfounded concerns with child safety to an obsession with academic achievement, today's overparents shape the experiences of childhood in ways that are often antithetical to healthy development. As Stearns (2004) suggested, "The $20^{\text {th }}$ century, once rated as the "century of the child," became rather a century of anxiety about parents' own adequacy. And children did not necessarily benefit from this process of adult debate and self-doubt" (p. 1).

Overly involved or protective parenting, sometimes labelled overparenting, has received increasing attention in popular culture for more than 20 years (Gibbs, 2009; Marano, 2008; Thomasgard, \& Metz, 1993); however, until recently there has been a scarcity of overparenting research to guide youth program practices (Locke, Campbell, \& Kavanagh, 2012; Segrin, Woszidlo, Givertz, Bauer, \& Taylor-Murphy, 2012). Parental involvement and engagement are foundational to positive youth development settings and outcomes (Hoover-Dempsey, \& Sandler, 1995; Fan, \& Chen, 2001; Jeynes, 
2005). Research supports the importance of parental involvement in youth programs (Ferreri, Futris, Smathers, Cochran, Arnett, \& Digby, 2006), and likewise has demonstrated that lack of parental responsiveness (Carruthers, \& Busser, 2000) and parental non-participation (Culp, 1998) are common challenges faced by youth program providers.

But what influence-positive or negative-might overparenting have on youth programs? Because most overparenting research has been confined to clinical settings, studies of young children, and studies of college students, it is important to investigate this parenting approach in naturalistic youth program settings. As such this paper has two aims: (list)

(1) to propose a conceptual model of overparenting based on a synthesis of contemporary literature, and

(2) to explore overparenting within the context of positive youth development to provide considerations for future research on the influence of overparenting on the quality of youth development programs.

We propose that overparents may exert specific pressures on youth program providers thus impacting program quality across a number of programmatic and organizational dimensions.

\section{Normative Parenting}

Children need supportive relationships with caring adults to help them negotiate childhood, adolescence, and a successful transition to adulthood (Eccles, \& Gootman, 2002; Roth, \& BrooksGunn, 2003). Although parents and non-parental adults both play a role in providing youth with a variety of supports and opportunities that facilitate healthy outcomes and ameliorate negative influences (Bowers, et al., 2014), the presence of parents is particularly impactful (Bean, Bush, McKenry, \& Wilson, 2003; Bowers, et al., 2011; Hart, Newell, \& Olson, 2003). Normative parenting is predictive of child well-being in the domains of social competence, academic performance, psychosocial development, and problem behavior (Darling, 1999).

Baumrind (1967) created the first parenting style typology, with dimensions that included authoritative, authoritarian, and permissive parenting. Maccoby and Martin (1983) expanded and updated Baumrind's model by substituting indulgent and neglectfu/ in place of permissive. Steinberg and his colleagues (Gray, \& Steinberg, 1999; Steinberg, 1990) separated authoritative parenting into three distinct components: acceptance, behavioral control, and psychological control. Darling and Steinberg (1993) proposed that parental goals and values influenced both parenting style and practice. In their model parenting practice refers to the specific behavior that a parent uses to socialize children, whereas parenting style is the emotional climate in which a child is raised (Darling, \& Steinberg, 1993).

Through a contemporary analysis of the parenting dimensions and typologies to date, Hart, et al., (2003) proposed three distinguishing dimensions of normative parenting, including:

(a) warmth and support shown to a child to facilitate an emotional connection (e.g., acceptance, affection, involvement, nurturance),

(b) behavioral contro/ of the child to foster mature behavior (e.g., limit setting, supervision, reasoning about consequences), and

(c) autonomy granting (e.g., independence, self-governance) to promote emotional and psychological self-reliance.

There has been renewed interest in understanding the role of control and autonomy granting as part of the "recent trend in parenting research toward disaggregating parenting typologies to better understand the unique effects of their constituent components" (p. 3). 


\section{Overparenting}

Definitions

Non-normative, yet effortful parenting has been described using a variety of terms, including: helicopter parenting (Padilla-Walker, \& Nelson, 2012; Segrin, et al., 2012;), intrusive parenting (Taylor, Eisenberg, Spinrad, \& Widaman, 2013), over-protective parenting (Spokas, \& Heimberg, 2009; Thomasgard, \& Metz, 1993; Ungar, 2009), oversolicitous parenting (Rubin, Hastings, Stewart, Henderson, \& Chen, 1997), lawnmower parenting (Locke, Campbell, \& Kavanagh, 2012; Segin, et al., 2012), overly effortful parenting (Locke, et al., 2012), and overparenting (Locke, et al., 2012; Munich, $\&$ Munich, 2009). Although similar, these terms are often used in conceptually different ways and researchers have noted that the meanings of these non-normative parenting approaches is unclear (Segrin, et al., 2012; Taylor, et al., 2013).

The helicopter parent (sometimes labeled as overprotective or over-solicitous) is defined as a parent who excessively shields and problem-solves for his/her child rather than allow the child to experience failure or challenge. In this way, the helicopter parent prevents his/her child from demonstrating personal growth (Bradley-Geist, \& Olson-Buchanan, 2014; Segrin, et al., 2012; Segrin, Woszidlo, Givertz, \& Montgomery, 2013). Padilla-Walker and Nelson (2012) conceptualized the helicopter parent as one that is "high on warmth/support, high on control, and low on granting autonomy" (p. 1178). To date the majority of research into the construct of helicopter parenting has focused on adolescents and emerging adults (Padilla-Walker, \& Nelson, 2012; Segrin, et al., 2012; 2013), the intrusive parent (sometimes called an overly-effortful parent) over-schedules and micromanages their children, discouraging free time and independent behavior. Intrusive parents often function poorly without their child (Padilla-Walker, \& Nelson, 2012; Thomasgard, \& Metz, 1993). The lawnmower parent quite literally "mows" problems out of their child's path (Locke, et al., 2012). They seek to remove all perceived obstacles from their child's growth and are frequently cited as interfering with academics and athletics to excess. We recognize overparenting as the term that best represents nonnormative, yet effortful (as opposed to permissive) parenting styles. Segrin, et al., (2013), offering what may be the most cogent definition of an overparent, suggested that "individuals who enact this form of parenting appear hyper-involved in their children's lives, risk averse, and preoccupied with their children's emotional well-being" (p. 570-571). Put simply, overparenting suggests "behaviors beyond what most parents would do" (Thomasgard, \& Metz, 1993, p. 67).

\section{Conceptual and Theoretical Foundations}

While early parenting style typologies by Baumrind, (1967) and Maccoby and Martin (1983) did not account for overparenting, current theory and research (Locke, et al., 2012; Taylor, et al., 2013) suggests that evidence of overparenting may be seen across these styles. Thus, today's overparent may reflect a combination of parenting styles or a unique and understudied pattern of parenting dimensions. Taylor, et al., (2013) proposed that the overparent construct may exist along a continuum between authoritative, authoritarian, and indulgent parenting. Conceptualizing overparenting on a continuum is consistent with the views of Padilla-Walker and Nelson (2012), who stressed that helicopter parenting did not reflect an entirely new dimension of parenting, but rather that it represented a "unique patterning of the basic dimensions of parenting" (p. 1178). Further, Padilla-Walker and Nelson theorized that parents often display a combination of styles; demonstrating overparenting in one aspect of their child's life (athletics for example) and not in another aspect of their child's life (academics for example). Similarly, Bowers, et al., (2014) proposed a parent profile that reflected "maximum plasticity" (p. 912) to allow parents the capacity to contextually adapt parenting behaviors based on the time and place they were interacting with their child. 
Family enmeshment theory and attachment theory have informed the construct of overparenting. Family enmeshment theory, which posits that parents use their children to satisfy their own incomplete goals, regrets, or anxieties, provides a motivational basis for overparenting. From the enmeshment perspective, parents project their own goals onto their child, excessively control their child's life, and vicariously experience their child's successes and failures (Segrin, et al., 2013). Attachment theory posits that insecure parenting behavior, for example becoming overly-involved or overly-controlling in a child's life, is associated with negative outcomes for children including increased anxiety, stress regulation, and low self-efficacy (Sideridis, \& Kafetsios, 2008). Indeed, Padilla-Walker and Nelson (2012) noted that helicopter parenting shares characteristics of control driven by parental separation anxiety. In these situations, parents may be more concerned with their own experience of separation than they are about the experiences of their child.

Contemporary family structures and parental pressures are often hypothesized to be motivators of overparenting. Carney-Hall (2008) proposed that parents have become overinvolved because family support systems are now more diverse, with increases in divorced, blended, single-parent, or samesex families. Munnich and Munnich (2009) suggested that overparenting is a response to expectations associated with contemporary standards of achievement and academic and economic success, and that this pressure becomes the main rationalization for over-structuring and micromanaging the child and adolescent's life. Summarizing research conducted by Stuart Brown with the National Institute for Play, Munnich and Munnich (2009) explained,

...the level of parenting involvement in structuring every minute of a child's day, their effort to eradicate rough-and-tumble play in boys, and their efforts to oversanitize all areas where children recreate has the potential of seriously curtailing other areas of development, such as the ability to pursue curiosity, explore, and assess their own sense of risk and safety, and thus establish their own borders and boundaries with the outside world (p. 234-235).

In fact, further investigation by Segrin, et al., (2013) and Wolfradt, Hempel, and Miles (2003) suggests that overparents themselves may possess negative attributes including anxiety, narcissism, and feelings of entitlement.

The broader socio-cultural context of modern parenting exerts powerful influences on many overparenting behaviors, and this context may be the cause of parental anxiety that contributes to overparenting. As Munich and Munich (2009) note,

It begins with exhortations and techniques to maximize early childhood stimulation (Baby Einstein) and includes protective devices such as anti-bacterial products and "nanny-cams," pre-school academic enhancers for reading and math, self-esteem promoters as in excessive birthday parties and graduation ceremonies from nursery school, a $\$ 4$ billion dollar tutoring industry that begins in elementary school, strenuous programs for extracurricular and athletic activities, special skills camps and, by late in high school, hiring private admissions counselors at great expense to help market the child to the best possible college (p. 234).

For many parents, pressures for academic success become the main rationalization for overstructuring, micromanaging, and close scheduling of a young persons' life.

Another source of parental anxiety may come from perceived risk associated with childhood experiences. Researchers have suggested that uncertainty associated with modern life has 
contributed to the development of a risk society (Scott, Jackson, \& Backett-Milburn, 1998). In a risk society, parents are constantly engaged in assessing and managing risk in all areas of their child's life. There is an ongoing call for a closer examination of how risk is embedded in specific contexts (Scott, et al., 1998), how risks are socially constructed within families (Backett-Milburn, \& Harden, 2004), and how these perceived risks contribute to risk anxiety in parents. Although occasional anxious feelings are a universal quality of human nature, understanding parental risk anxiety and the fears that parents associated with childhood experiences are important because parental fears may influence how parents allow their children to play (Scott, et al., 1998). Limits on childhood experiences due to parental fears and risk anxiety may thus impede healthy child development, particularly when parents act as gatekeepers of their child's experiences in order to maintain power over their children (Hood-Williams, 1990).

\section{Overparenting and Youth Programs}

While normative parenting styles can result in positive youth outcomes, such as adjustment and competence (Baumrind, 2005), overparenting can lead to variety of negative youth outcomes (PadillaWalker, \& Nelson, 2012) such as poor self-regulation and childhood anxiety (Segrin, et al., 2012; Sideridis, \& Kafetsios, 2008). Research suggests that overparenting contributes to the development of a cognitive style (in a child) in which a child comes to believe that personal success or failure are largely determined by external factors (Spokas, \& Heimberg, 2009), as opposed to being within one's control. In this case, low feelings of self-efficacy and autonomy can lead to poorer outcomes for a child later in life (Baumrind, 2005, Taylor, et al., 2013) such as difficultly in the development of peer relationships (Rubin, Burgess, \& Hastings, 2002) and social withdrawal (Bayer, Sanson, \& Hemphill, 2006).

From the perspective of youth program management, these challenging participant behaviors can directly interfere with successful program implementation in a variety of ways. At the most basic level, parents that display an overparenting style are difficult within the context of a youth program setting because they may feel uncomfortable with how the program might affect their child, from being too challenging to being too easy. Parents may also be concerned with how their child's performance within that youth program settings is reflecting on their own parenting skills or selfworth. Coakley (2006) discussed the idea that a child's performance reflects their parents' perceived level of commitment. When a child succeeds their parent was "committed," but when the child fails the parent was not committed enough; "sports come to symbolize one's moral worth as parent" ( $p$. 260). Overparents may pass this self-induced pressure and anxiety on to youth program providers to ensure their child succeeds. Overparents may also negatively influence the manner in which programs are delivered, either by siphoning off facilitator time and attention managing their specific issues or altering the design and implementation of a program because of their concerns. When considering these challenges in the context of program evaluation, overparents may have a significant negative influence on the fidelity to which programs are delivered, thereby compromising the corresponding intended outcomes.

The relationship between overparenting and childhood anxiety-one of the most common disorders in children (Ragnell, 2011) -is suggested by the literature on childhood homesickness. Homesickness, "the distress or impairment caused by an actual or anticipated separation from home" (Thurber, \& Sigman, 1998, p. 904), has been shown to be strongly related to both child (Thurber, 2005) and parental anxiety (Thurber, \& Walton, 2007). In one of the few studies that investigated the role of parent anxiety on children's anxiety symptoms within the context of a youth program, Kingery, Peneston, Rice, and Wormuth (2012) examined parents' concerns about sending their children to camp and children's anxiety symptoms in predicting homesickness during overnight summer camp. The researchers found that parental anxious expectations were associated with child homesickness 
and was a unique predictor in the regression model. This study was unique in that it focused on parents' anxious expectations about camp rather than parents' anxiety about separating from their children in general. The researchers, citing Fisak and Grills-Taquechel (2007), proposed that parents may influence their children through modeling or verbal instructions, an approach reflecting Bandura's Social Learning Theory (1986). Similarly, Thurber and Sigman (1998) found that boys who experienced more homesickness have parents who reported greater separation anxiety about sending their child to camp. Research associating homesickness and parent anxiety is compelling, and may have implications for overparenting. Although this study did not explicitly mention overparenting, the emphasis on parents with high expectations and anxiety is consistent with other descriptions of overparents (Padilla-Walker, \& Nelson, 2012; Sideridis, \& Kafetsios, 2008). Reducing overparenting behaviors, and thus parent and child anxiety, may reduce homesickness.

Not all research suggests that a highly-involved parenting style, which is conceptually similar to overparenting, always leads to negative youth outcomes. In fact, highly involved and warm parenting has been associated with higher levels of positive youth development and a higher likelihood that a child is connected to an important non-parental adult (Bowers, et al., 2014). Furthermore, children who have authoritative parents have a lower risk for engaging in drug and heavy alcohol use (Stephenson, \& Helme, 2006), delinquency (Johnson, Giordano, Manning, \& Longmore, 2011), and homelessness (van de Bree, Shelton, Bonner, Moss, Thomas, \& Taylor, 2009) later in life.

Considering this variability in the overparenting research, we need to better understand what differentiates a supportive parent which is associated with positive outcomes (See Baumrind, 2005) and an overparent which is associated with negative outcomes including maladjustment (Segrin, et al., 2012; 2013), poor stress regulation, and as previously mentioned, anxiety (Sideridis, \& Kafetsios, 2008). Today's overparent may reflect a unique pattern of parenting dimensions that are not accurately or adequately described within the current literature. Theoretical models and applied research are needed to inform the practice of youth work (Lerner, et al., 2011). Greater awareness of overparenting within youth development programs may inform the extent to which overparenting influences positive or negative youth, program, and organizational outcomes and may also identify promising practices for the effective management of overparents.

\section{Conceptual Model of Overparenting within Youth Development Programs}

Positive youth development emphasizes the provision of appropriate supports and opportunities (Eccles, \& Gootman, 2002) that enhance existing youth assets. From this perspective, normative parenting is viewed as a critical "support" for promoting positive youth development and youth involvement in programs and activities that provide access to supportive adults and skill-building experiences are "opportunities" that contribute to positive developmental outcomes. In an exhaustive review of the literature, Catalano, Berglund, Ryan, Lonczak, and Hawkins (2004) identified 15 programmatic positive youth development outcomes, including: (1) promotes bonding, (2) fosters resilience, (3) promotes social competence, (4), promotes emotional competence, (5) promotes cognitive competence, (6) promotes behavioral competence, (7) promotes moral competence, (8) fosters self-determination, (9) fosters spirituality, (10) fosters self-efficacy, (11) fosters clear and positive identity, (12) fosters belief in the future, (13) provides recognition for positive behavior, (14) provides opportunities for prosocial involvement, and (15) fosters prosocial norms.

Figure 1 shows a proposed model for understanding overparenting within the context of a youth development program based on current research and theory. This model organizes existing overparenting-related terms and operationalizes the construct. In this model, parenting is viewed in accordance with Fox's (1994) definition as "a dynamic process that includes the unique behaviors of a parent that a child directly experiences and that significantly impact his or her development. 
Parenting also includes parental expectations which children directly experience through their parents' behaviors" (p. 3). Normative parenting is represented according to Hart, et al., (2003) conceptualization of support, behavioral control, and autonomy granting, while overparenting is theorized to involve high levels of parental support, behavioral control, and anxiety, and low levels of autonomy granting. Thus, overparenting is viewed to exist as a unique pattern of dimensions that reflect: level of support, control and autonomy granting demonstrated by parents. Specifically, overparenting is defined as a unique pattern of parental behaviors characterized by high support, high control, and low autonomy granting and high parental expectations that is excessively protective and controlling of a child's youth development experiences.

Figure 1

Conceptual Model of Overparenting Influences on Youth Development Programs

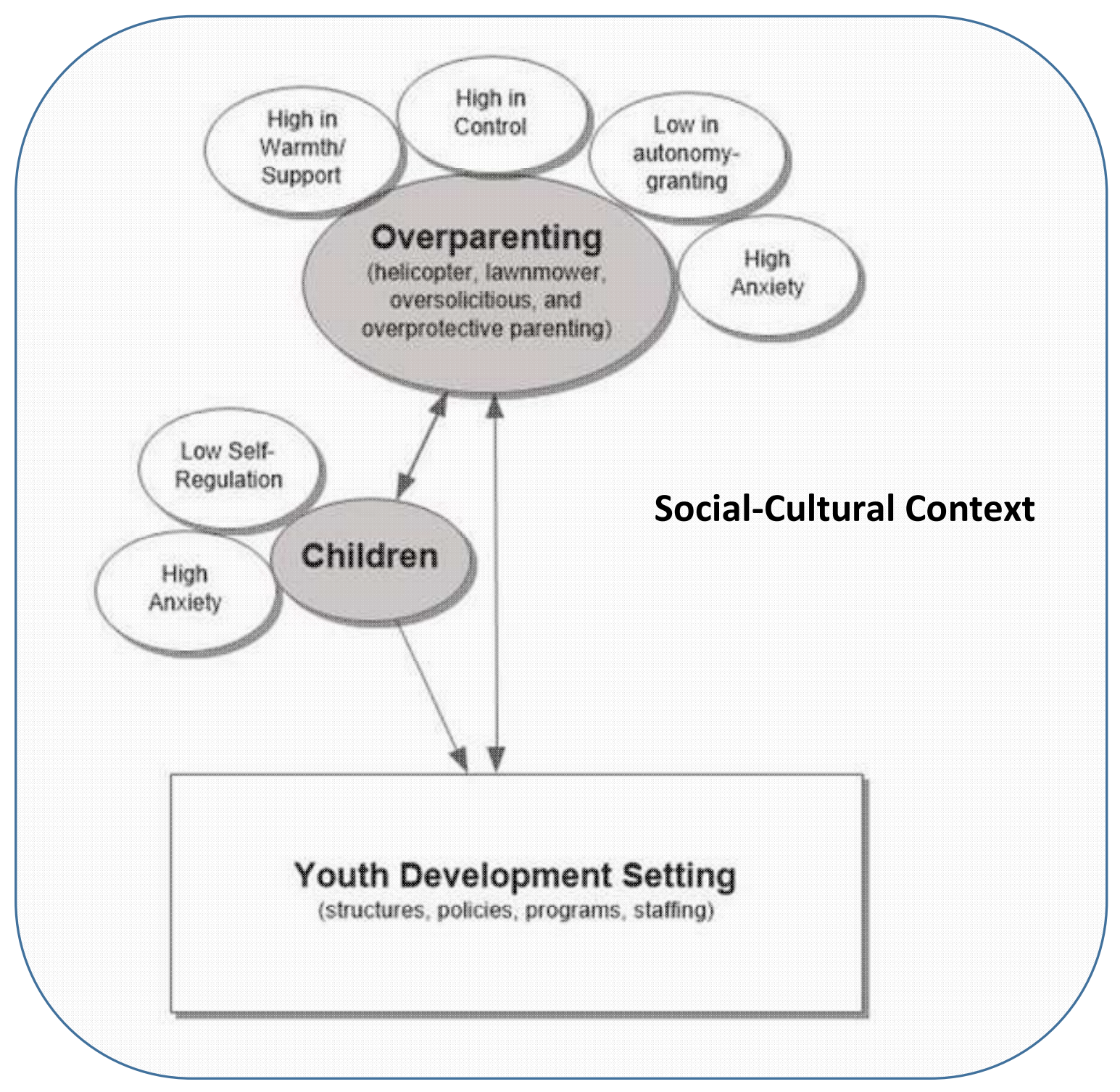

We recognize the bidirectional relationship that exists between parental influences on youth and youth influences on parents (Lerner, 1982), and we propose that a similar bidirectional relationship may exist between overparents and program providers. At the youth development organizational 
level, we propose that overparents may influence structures, policies, programs, and/or staffing, and similarly that program providers (through the structures, policies, programs, and/or staffing systems they implement) may also influence parents. We view these concepts to be fluid rather than static, and we recognize that parental behaviors may vary based on the nature of the parenting role they may express at any given time, which would also apply to situations in which they are interacting with their child within the context of a youth development program.

\section{Implications for Research and Practice}

The majority of overparenting-related research has been confined to clinical settings (Locke, et al., 2012) or higher education settings (Padilla-Walker, \& Nelson, 2012). These studies often focus on early adulthood (Segrin, et al., 2012; 2013), but there is evidence that overparenting may also be prevalent among parents of middle and high-school aged youth. As previously noted, Kingery, et al's (2012) study of homesickness and parent anxiety suggests the influence of non-normative parenting. Given that the majority of research into child and parental anxiety is conducted in clinical settings (Chavira, Stein, Bailey, \& Stein, 2004); it is important to investigate these concepts in a more naturalistic setting, for example in an after-school program, summer camp, or other out-of-schooltime youth program where homesickness may be a common issue requiring staff management and the allocation of organizational resources. For example, a recent survey of 536 youth program providers found that parent communication was the most important issue that directors and frontline staff had to manage (American Camp Association, 2013). Furthermore, directors reported that many parents expected increased communication with the director, frequent updates about their child's experience, opportunities to communicate with their child, and access to pictures of their child participating in the program. Expectations like these may reflect overparenting behaviors and may be management issues that impact program implementation.

The influence of overparenting on the implementation of youth development programs is unclear, but anecdotal evidence (American Camp Association, 2013) suggests that overparents influence the programs in which their children participate. What we do know is that children of overparents are more likely to have children who show childhood anxiety and maladaptive, challenging behaviors, and these behaviors may manifest during the youth program in which those children participate. In a youth program setting the influence of overparents may be experienced not only by parents' own children, but also by other program participants. Furthermore, overparents may influence youth program providers' operational, managerial, or programmatic planning that may have broad impacts on all program participants.

Conversely, overparents may also have positive influences on youth programs. Carney-Hall (2008) noted the positive role that parents can play as student advocates. As program providers seek to meet the high expectations often associated with over-involved, over-protective parents, there may be improvement or enhancements in organizational practices or program components that contribute to overall program quality. Positive or negative, further examination of the influence of overparents on program planning, implementation, and other operational and programmatic dimensions necessary to understand their true effect.

Current research into overparents is also limited by the populations being investigated. With practically all of the overparenting research examining parenting within the context of clinical or higher education settings, the time has come to explore overparenting within the context of the most commonplace youth programs. The 1999 National Survey of America's Families found that 81\% of 611 year olds and $83 \%$ of $12-17$ year olds participated in one or more sports, lessons, or clubs during 
the past year (Ehrle, \& Moore, 1999). With approximately 8.4 million children enrolled in after-school programs (Afterschool Alliance, 2014), and millions more participating in community-based programs and youth organizations, there are many programs and contexts in which to examine possible influences of overparenting on program quality.

A richer understanding of overparenting within youth programs will also require development of measures of overparenting. While parenting measures have been informed by decades of research, as noted earlier the examination of overparenting has much less history (Locke, et al., 2012; PadillaWalker, \& Nelson, 2012; Segrin, et al., 2012; 2013). Existing measures of parenting behavior have been largely retrospective and limited by the homogenous nature of the populations being investigated. We propose parenting measures that examine behaviors at the parent-child level and also within the context of youth programs. These measures could help program providers identify overparents prior to program implementation and assist program providers in addressing or redirecting parental concerns.

Furthermore, we propose future overparenting research that considers the broader socio-cultural context of parenting within youth development programs. Research suggests that parenting differs among ethnic groups (Dexter, Wong, Stacks, Beeghly, \& Barnett, 2013), socioeconomic (Dotterer, Iruka, \& Pungello, 2012), and cultural groups (Bornstein, 2012). Thus, we envision a research agenda that explores how overparenting may be manifest across different cultural, ethnic, and racial groups to determine if current conceptualizations of overparenting fit diverse parent groups. Given the homogenous nature of populations that have been currently been researched we may find the manner in which overparenting is conceptualized may be very different depending on parents' demographic profiles.

\section{References}

Afterschool Alliance. (2014). America After 3PM: Afterschool Programs in Demand. Washington. D.C. American Camp Association (2013). 2013 Camp Emerging Issues and Trends Survey. American Camp Association.

Bandura, A. (1986). The explanatory and predictive scope of self-efficacy theory. Journal of Clinical and Social Psychology, 4, 359-373.

Baumrind, D. (1967). Child care practices anteceding three patterns of preschool behavior. Genetic Psychology Monographs, 75(1), 43-88.

Baumrind, D. (2005). Patterns of parental authority and adolescent autonomy. New Directions for Child and Adolescent Development, 108, 61-69.

Bayer, J., Sanson, A., \& Hemphill, S. (2006). Parent influences on early childhood internalizing difficulties. Journal of Applied Developmental Psychology, 27, 542-559.

Bean, R.A., Bush, K.R., McKenry, P.C., \& Wilson, S.M. (2003). The impact of parental support, behavioral control, and psychological control on the academic achievement and self-esteem of African American and European American adolescents. Journal of Adolescent Research, 18, 523-541. 
Bornstein, M.H. (2012). Cultural approaches to parenting. Parenting Science and Practice, $12(2), 212-221$.

Bowers, E.P., Johnson, S.K., Buckingham, M.H., Gasca, S., Warren, D.J., Lerner, J.V., \& Lerner, R.M. (2014). Important non-parental adults and positive youth development across mid-to-late adolescence: The moderating effect of parenting profiles. Journal of Youth and Adolescence, 43, 897918.

Bowers, E.P., von Eye, A., Lerner, J.V., Arbeit, M.R., Weiner, M.B., Chase, P., \& Agans, J.A. (2011). The role of ecological assets in positive and problematic developmental trajectories. Journal of Adolescence, 34, 1151-1165.

Bradley-Geist, C., \& Olson-Buchanan, J. (2014). Helicopter parents: An examination of the correlates of over-parenting of college students. Education + Training, 56(4), 314-328.

Carney-Hall, K.C. (2008). Understanding current trends in family involvement. New Directions for Student Services, 122, 3-14.

Catalano, R.F., Berglund, L., Ryan, J.A., Lonczak, H.S., \& Hawkins, J.D. (2004). Positive youth development in the United States: Research findings on evaluations of positive youth development programs. The Annals of the American Academy of Political and Social Science, 591, 98-124.

Chavira, D.A., Stein, M.B., Bailey, K., \& Stein, M.T. (2004). Child anxiety in primary care: Prevalent but untreated. Depression and Anxiety, 20, 155-164.

Carruthers, C.P., \& Busser, J.A. (2000). A qualitative outcome study of boys and girls club program leaders, club members, and parents. Journal of Park and Recreation Administration, 18(1), 50-67.

Coakley, J. (2006). The good father: Parental expectations and youth sports. Leisure Studies, 25(2), 153-163.

Culp, R.H. (1998). Adolescent girls and outdoor recreation: A case study examining constraints and effective programming. Journal of Leisure Research, 30(3), 356-379.

Darling, N. (1999). Parenting Style and its Correlates. Eric Digest. Champaign IL: ERIC Clearinghouse on Elementary and Early Childhood Education.

Darling, N., \& Steinberg, L. (1993). Parenting style as context: An integrative model. Psychological Bulletin, 113(3), 487-496.

Dexter, C.A., Wong, K., Stacks, A.M., Beeghly, M., \& Barnett, D. (2013). Parenting and attachment among low-income African-American and Caucasian preschoolers. Journal of Family Psychology, 27(4), 629-638.

Dotterer, A.M., Iruka, I.U., \& Pungello, E. (2012). Parenting, race, and socioeconomic status: Links to school readiness. Family Relations, 61, 657-670.

Eccles, J.S. \& Gootman, J.A. (2002). Community programs to promote youth development. Washington, DC: National Academies Press. 
Ehrle, J., \& Moore, K. (1999). 1997 NSAF benchmarking measures of child and family well-being. Washington, DC: The Urban Institute, Assessing the New Federalism Methodology, Report No. 6.

Fan, X., \& Chen, M. (2001). Parental involvement and students' academic achievement: A metaanalysis. Educational Psychology Review, 13(1), 1-22.

Ferreri, T.M., Futris, T.G., Smathers, C.A., Cochran, G.R., Arnett, N., \& Digby, J.K. (2006).

Parents' perceptions of family involvement and youth outcomes at an urban 4-H education center.

The Forum for Family and Consumer Issues, 11(2). Retrieved from

http://ncsu.edu/ffci/publications/2006/v11-n2-2006-december/fa-1-parents.php.

Fisak, B., \& Grills-Taquechel, A.E. (2007). Parental modeling, reinforcement, and information transfer: Risk factors in the development of child anxiety. Clinical Child and Family Psychology, 10(3), 213-231.

Fox, R. (1994). Parent Behavior Checklist Manual. Austin, TX: Pro-Ed.

Gibbs, N. (2009, November 20). The Growing Backlash against Overparenting. Time, 1-7.

Gray, M.R., \& Steinberg, L. (1999). Unpacking authoritative parenting: Reassessing a multidimensional construct. Journal of Marriage and the Family, 61, 574-587.

Hart, C.H., Newell, L.D., \& Olsen, S.F. (2003). Parenting skills and social-communicative competence in childhood. In J.O. Greene, \& B.R. Burleson (Eds.), Handbook of communication and social interaction skills (pp. 753-797). Mahwah, NJ: Erlbaum.

Hood-Williams, J. (1990). Patriarchy for Children: On the Stability of Power Relations in Lives, in L. Chisholm, P. Büchner, H-H. Krüger, \& P. Brown (eds.), Children, Youth and Social Change: $A$ Comparative. London: Falmer.

Hoover-Dempsey, K.V., \& Sandler, H.M. (1995). Parental involvement in children's education: Why does it make a difference? Teachers College Record 972), 310-31.

Jeynes, W.H. (2005). A meta-analysis of the relation of parental involvement to urban elementary school student academic achievement. Urban Education, 40(3), 237-269.

Johnson, W.L., Giordano, P.C., Manning, W.D. \& Longmore, M.A. (2011). Parent-child relations and offending during young adulthood. Journal of Youth and Adolescence 40, 786-99.

Kingery, J.N, Peneston, K.R., Rice, S.E., \& Wormuth, B.M. (2012). Parental anxious expectations and child anxiety predicting homesickness during overnight summer camp. Journal of Outdoor Recreation, Education, and Leadership, 4(3), 172-184.

Lerner, R.M. (1982). Children and adolescents as producers of their own development. Developmental Review, 2, 342-370.

Lerner, R.M., Lerner, J.V., Lewin-Bizan, S., Bowers, E.P., Boyd, M., Mueller, M., Schmid, K., Napolitano, C. (2011). Positive youth development: Processes, programs, and problematics. Journal of Youth Development, 6(3), 40-64. 
Locke, J.Y., Campbell, M.A., \& Kavanagh, D. (2012). Can a parent do too much for their child? An examination by parenting professionals of the concept of overparenting. Australian Journal of Guidance and Counselling, 22(2), 249-265.

Maccoby, E.E., \& Martin, J.A. (1983). Socialization in the context of the family: Parent-child interaction. In P.H. Mussen \& E.M. Hetherington, Handbook of child psychology: Vol. 4. Socialization, personality, and social development (4th ed.). New York: Wiley.

Marano, H. (2008). A nation of wimps: The high cost of invasive parenting. New York: Broadway Books.

Munnich, R.L. \& Munnich, M.A. (2009). Overparenting and the narcissistic pursuit of attachment. Psychiatric Annals, 39(4), 227-235.

Padilla-Walker, L.M., \& Nelson, L.J. (2012). Black hawk down?: Establishing helicopter parenting as a distinct construct from other forms of parental control during emerging adulthood. Journal of Adolescence, 35, 1177-1190.

Ragnell, A.L. (2011). Anxiety and separation disorders. Pediatrics in Review, 32(10), 440-446.

Roth, J., \& Brooks-Gunn, J. (2003). Youth development programs: Risk, prevention and policy. Journal of Adolescent Health, 32(3), 170-182.

Rubin, K.H., Burgess, K.B., \& Hastings, P.D. (2002). Stability and social-behavioral consequences of toddlers' inhibited temperament and parenting behaviors. Child Development, 73, 483-495.

Rubin, K.H., Hastings, P.D., Stewart, S.L., Henderson, H.A., \& Chen, X. (1997). The consistency and concomitants of inhibition: Some of the children, all of the time. Child Development, 68, 467- 483.

Savage, J. (2007). Teenage: The Creation of Youth Culture. New York, NY: Viking Books.

Scott, S., Jackson, S., \& Backett-Milburn, K. (1998). Swings and roundabouts: Risk anxiety and the everyday worlds of children. Sociology, 32(4), 689-705.

Segrin, C., Woszidlo, A., Givertz, M., \& Montgomery, N. (2013). Parent and child traits associated with overparenting. Journal of Social and Clinical Psychology, 32(6), 569-595.

Segrin, C., Woszidlo, A., Givertz, M., Bauer, A., \& Taylor-Murphy. M. (2012). The association between overparenting, parent-child communication, and entitlement and adaptive traits in adult children. Family Relations, 61, 237-252.

Sideridis, G.D., \& Kafetsios, K. (2008). Perceived parental bonding, fear of failure and stress during class presentations. International Journal of Behavioral Development, 32, 119-130.

Spokas, M., \& Heimberg, R.G. (2009). Overprotective parenting, social anxiety, and external locus of control: Cross-sectional and longitudinal relationships. Cognitive Therapy and Research, 33, 543-551.

Stearns, P. (2004). Anxious Parents: A History of Modern Child-Rearing in America (pp. 1-231). New York: New York University Press. 
Steinberg, L. (1990). Interdependency in the family: Autonomy, conflict, and harmony. In S. Feldman, \& G. Elliot (Eds.), At the threshold: The developing adolescent (pp. 255-276). Cambridge, MA: Harvard University Press.

Stephenson, M.T. \& Helme, D.W. (2006). Authoritative parenting and sensation seeking as predictors of adolescent cigarette and marijuana use. Journal of Drug Education, 36, 247-70.

Taylor, Z.E., Eisenberg, N., Spinrad, T.L., \& Widaman, K.F. (2013). Longitudinal relations of intrusive parenting and effort control to ego-resiliency during early childhood. Child Development, 84(4), 11451151.

Thomasgard, M., \& Metz, P. (1993). Parental overprotection revisted. Child Psychiatry and Human Development, 24(2), 67-80.

Thurber, C.A. (2005). Multimodal homesickness prevention in boys spending 2 weeks at a residential summer camp. Journal of Consulting and Clinical Psychology, 73(3), 555-560.

Thurber, C.A., \& Sigman, M.D. (1998). Preliminary models of risk and protective factors for childhood homesickness: Review and empirical synthesis. Child Development, 69, 903-934.

Thurber, C.A., \& Walton, E. (2007). Preventing and treating homesickness. American Academy of Pediatrics. 119(1), 192-201.

Tough, P. (2012). How Children Succeed: Grit, Curiosity and the Hidden Power of Character. Houghton Mifflin Harcourt.

Ungar, M. (2009). Overprotective parenting: Helping parents provide the right amount of risk and responsibility. The American Journal of Family Therapy, 37, 258-271.

van de Bree, M.B.M., Shelton, K., Bonner, A., Moss, S., Thomas, H. \& Taylor, P.J. (2009). A longitudinal population-based study of factors in adolescence predicting homelessness in young adulthood. Journal of Adolescent Health, 45, 571-8.

Wolfradt, U., Hempel, S., \& Miles, J.N.V. (2003). Perceived parenting styles, depersonalization, anxiety and coping behavior in adolescents. Personality and Individual Differences, 34, 521-532.

(C) Copyright of Journal of Youth Development Bridging Research and Practice. Content may not be copied or emailed to multiple sites or posted to a listserv without copyright holder's express written permission. Contact Editor at: patricia.dawson@oregonstate.edu for details. However, users may print, download or email articles for individual use.

ISSN 2325-4009 (Print); ISSN 2325-4017 (Online) 